\title{
Quality Measures for the Diagnosis and Non-Operative Management of Carpal Tunnel Syndrome in Occupational Settings
}

\author{
Teryl Nuckols • Philip Harber - Karl Sandin • Douglas Benner • \\ Haoling Weng • Rebecca Shaw • Anne Griffin • Steven Asch • \\ The Carpal Tunnel Quality Group
}

Published online: 25 August 2010

(C) The Author(s) 2010. This article is published with open access at Springerlink.com

\begin{abstract}
Introduction: Providing higher quality medical care to workers with occupationally associated carpal tunnel syndrome (CTS) may reduce disability, facilitate return to work, and lower the associated costs. Although many workers' compensation systems have adopted treatment guidelines to reduce the overuse of unnecessary care, limited attention has been paid to ensuring that the care workers do receive is high quality. Further, guidelines are not designed to enable objective assessments of quality of care. This study sought to develop quality measures for the diagnostic
\end{abstract}

Members of the Carpal Tunnel Quality Group include Denis Chagnon, MD (Family Practice, Albany Memorial Hospital); Walter Chang, MD

(Kaiser Permanente Medical Group, Yorba Linda, CA); Jeff Harris, MD (Occupational Medicine, Kaiser Permanente Medical Group, Northern California); Neil Harness, MD (Kaiser Permanente Medical Group,

Fontana, CA); Charles Jablecki, MD (Neurology, La Jolla, CA); David Kilmer, MD (deceased; previously Physical Medicine and Rehabilitation, University of California, Davis); Peter Mandell, MD (Orthopedics, Burlingame, CA), Daniel Mass, MD (Hand Surgery, University of Chicago); Victoria Masear, MD (Hand Surgery, Birmingham, AL); Kevin Chung, MD (Hand Surgery, University of Michigan, Ann Arbor, MI); Mark Melhorne, MD (Hand Surgery, Wichita, KS); Cuong Pho, DPT (Physical Therapy, Kaiser Permanente, Harbor City, CA); and Rick Strain, MD (Orthopedics, Hollywood, FL).

T. Nuckols $(\bowtie) \cdot$ R. Shaw $\cdot$ A. Griffin $\cdot$ S. Asch

Health Services Researcher, RAND Corporation, 1776 Main St,

P.O. Box 2138, Santa Monica CA 90407-2138, USA

e-mail: tnuckols@mednet.ucla.edu

T. Nuckols $\cdot$ S. Asch

Division of General Internal Medicine and Health Services

Research, Department of Medicine, David Geffen School of

Medicine, University of California, Los Angeles, CA, USA

P. Harber

The Division of Occupational and Environmental Medicine, Department of Family Medicine, David Geffen School of Medicine at the University of California, Los Angeles, CA, USA evaluation and non-operative management of CTS, including managing occupational activities and functional limitations. Methods: Using a variation of the well-established RAND/UCLA Appropriateness Method, we developed draft quality measures using guidelines and literature reviews. Next, in a two-round modified-Delphi process, a multidisciplinary panel of 11 U.S. experts in CTS rated the measures on validity and feasibility. Results: Of 40 draft measures, experts rated $31(78 \%)$ valid and feasible. Nine measures pertained to diagnostic evaluation, such as assessing symptoms, signs, and risk factors. Eleven pertain to non-operative treatments, such as the use of splints, steroid injections, and medications. Eleven others address assessing the association between symptoms and work, managing occupational activities, and accommodating functional limitations. Conclusions: These measures will complement existing treatment guidelines by enabling providers, payers, policymakers, and researchers to assess quality of care for CTS in an objective, structured manner. Given the characteristics of previous measures developed with these methods, greater adherence to these measures will probably lead to improved patient outcomes at a population level.

P. Harber

UCLA Center for Occupational and Environmental Health,

UCLA School of Public Health, Los Angeles, CA, USA

K. Sandin

Sister Kenny Rehabilitation Institute, Minneapolis, MN, USA

K. Sandin

The Rehabilitation Institute at Santa Barbara, Santa Barbara, CA, USA

D. Benner

Regional Occupational Health, Kaiser Permanente Medical

Group, Northern California, CA, USA 
Keywords Carpal tunnel syndrome $\cdot$ Health care quality assurance $\cdot$ Standards

\section{Introduction}

Minimizing disability, inappropriate time off work, and their economic sequellae remain major goals of occupational medicine. Several studies have demonstrated the clinical and financial benefits of ergonomic, disability management, and return-to-work interventions [1-3]. In many states, workers' compensation systems have adopted guidelines to prevent workers from receiving treatments that appear unnecessary, may delay return to work, or may even be harmful. However, less attention has been paid to ensuring that injured workers receive the basic, essential medical care processes involved in making a correct diagnosis, alleviating symptoms, and addressing activities and functional limitations. Better quality medical care would benefit both workers and employers. In one randomized controlled trial in Spain, improving medical care for musculoskeletal conditions reduced time on temporary disability by $37 \%$, the percentage of temporarily disabled workers going onto permanent disability by $50 \%$, and total costs (including disability and medical care) by $37 \%$ [4]. Given the potential benefits to workers and employers, several provider organizations and payers would like to see quality assessment and improvement activities become more routine in occupational medicine.

Carpal tunnel syndrome (CTS) should be a key target for such activities because it is prevalent and costly, and because there is indirect evidence of quality deficits. CTS affects three out of every 10,000 full-time workers [5]. For each workers' compensation claim for CTS, employers pay a median of $\$ 1,468$ to $\$ 11,941$ (inflated to 2009), depending on whether surgery is performed $[6,7]$. Each worker with CTS experiences a cumulative loss of future earnings equal to $\$ 45,000$ to $\$ 89,000$ [8].

For patients with CTS, diagnostic evaluations and nonoperative management are highly variable, which may indicate care is of inconsistent quality. Recommended

Present Address:

H. Weng

Amgen Pharmaceuticals, Thousand Oaks, CA, USA

H. Weng

Division of Rheumatology, Department of Medicine, David Geffen School of Medicine, University of California,

Los Angeles, Los Angeles, CA, USA

S. Asch

Department of Medicine, VA Greater Los Angeles Healthcare System, Los Angles, CA, USA history and physical examination elements are performed inconsistently $[9,10]$, and physicians differ in the criteria they use to diagnose CTS [11]. This variability in care appears to affect when patients receive a CTS diagnosis and how long they stay off work. A Washington State study found that half of workers' compensation claims for CTS were initially filed for other conditions, and $20 \%$ of the time the CTS was not diagnosed until more than three months into the claim. Later diagnoses were associated with longer disability [6].

To evaluate quality of care for occupational disorders like CTS, specific quality measures are needed. Processoriented quality measures identify basic, well-established care processes that patients should or should not receive under specific circumstances. The purpose of such measures is not to advance the standard of care but rather to make existing standards explicit and measurable. Although guidelines and measures can both help to standardize and improve care, guidelines cannot be used to measure quality (other similarities and differences between guidelines and measures are explored below). For an occupational condition, a set of quality measures should consider both medical and occupational issues, such as whether a patient's symptoms are associated with occupational activities and how occupational activities should be modified. Existing sets of measures, such as one set for back pain, often neglect occupational considerations [12].

The objective of this study was to develop a set of quality measures that can be used to objectively assess the quality of the diagnostic evaluation and therapeutic management of CTS, with an emphasis on issues specific to occupational settings. We developed these measures using a variation of the well-established RAND/UCLA Appropriateness Method. A particular strength of this method is that it considers available literature but is able to overcome gaps in research evidence by rigorously synthesizing the experience of expert clinicians [13]. Randomized controlled trials do not exist for most health care processes [14], including for many aspects of care for CTS [15]. In such circumstances, syntheses of clinical expertise are a valid and important form of evidence. This is demonstrated by the fact that, in several studies addressing a variety of conditions, better adherence to measures developed using RAND/UCLA Appropriateness Method has been associated with improved patient outcomes [16-18].

\section{Materials and Methods}

Measure development is a three-step process: (1) developing draft measures by integrating guidelines and literature; and (2) refining and selecting measures, in this case 
using a variation of the RAND/UCLA panel method; and (3) testing the measures against a data source. We report the first two steps in this paper.

We also developed measures to assess the quality of electrodiagnostic testing [19], whether carpal tunnel release surgery is performed for appropriate indications [20], and the quality of peri-operative management; these measures are being reported elsewhere.

\section{Developing Draft Measures}

Developing draft measures was an iterative process involving collaboration among a rheumatologist, a physiatrist, two internists with expertise in quality measurement, and two hand surgeons, as well as a project advisory board that included five occupational medicine physicians.

First, we identified aspects of care relevant to improving quality for CTS (for example, the initial physical examination) using relevant clinical practice guidelines and other summary literature. We conducted a general literature search on CTS, updated a 2004 search for relevant guidelines by searching MEDLINE and the National Guidelines Clearinghouse, and accessed personal reference collections [21]. Team physicians reviewed the guidelines and literature, chose care processes that are likely to affect patient outcomes or that are widely recommended, then wrote draft measures.

Next, directed MEDLINE searches were conducted to identify evidence pertinent to the draft indicators. A reference librarian conducted the searches, and excluded case reports and animal studies. The searches included the terms carpal tunnel syndrome OR median neuropathy, with additional MeSH terms for specific subtopics: diagnosis (classification, severity, history, occupation, and tests), non-surgical treatment (therapy, drug therapy, rehabilitation), and return to work issues (disability, ergonomic, work). Team physicians sequentially reviewed titles, abstracts, and articles to assess relevance to each draft measure. Respectively, 1,635 citations were reviewed pertained to the diagnosis of CTS, 475 to non-surgical treatment, and 538 to return to work issues. Draft measures were refined, added, and deleted on the basis of search results.

Next, physicians summarized, for each draft measure, the evidence supporting the relationship between the care process and patient outcomes, emphasizing the highest quality evidence identified. Given most of the evidence was not high quality, we used a simplified classification scheme: level 1, randomized controlled trial; 2, observational study; and 3, case reports, case series and expert opinion. Where level 1 evidence was not available, the summary described a chain of evidence or clinical rationale.
Refining and Selecting Measures

Methods for refining and selecting quality measures were based on the RAND/UCLA Appropriateness Method, a multidisciplinary, two-round, modified-Delphi process that enables researchers to obtain a quantitative assessment that reflects the judgment of a group of experts. This method (explained below) has been used previously to develop quality measures for a wide variety of conditions and types of care. Additional background information and technical details about this method have been published previously $[13,22]$. The method has reproducibility consistent with that of well-accepted diagnostic tests like screening mammography-i.e., separate panels examining the same topic have produced similar recommendations (kappas $0.51-0.83)$. Further, the measures developed using this method have been shown to have content, construct, and predictive validity, as evidenced by the fact that measures have been consistent with the results of subsequent randomized controlled trials or associated with improved patient outcomes. For example, panel judgments about the appropriateness of carotid endarterectomy were consistent with the findings of a subsequent randomized trial [23]. For arthroplasty of the knee and hip, adherence to measures addressing the appropriateness of surgery was found to be associated with improved quality of life [18]. For vulnerable elders, adherence to quality measures developed using this method was found to be associated with improved survival [16].

To select panelists for the current study, we asked U.S. specialty societies to recommend physicians who are leaders in each specialty, and then we reviewed curriculum vitae, interviewed candidates, and contacted references. The panel had eleven members: an occupational medicine physician, a neurologist, a physiatrist, a family physician, a physical therapist, four hand surgeons (one with primary board designation in plastic surgery and three in orthopedic surgery), and two orthopedists. We chose this balance of specialties because panelists rated many measures pertaining to carpal tunnel release surgery as well as the diagnostic evaluation and non-operative management. Panelists represented a variety of geographic locations, expertise, and both academic and community practice settings.

The first round of ratings involved having panelists rate the measures at home. Panelists received the evidence summaries, draft measures, ballots, and instructions. During the second round, panelists met in person and research team members moderated discussions of each draft measure, the evidence, and first-round ratings. We used a modified-Delphi panel method, rather than a consensuspanel method that forces agreement, to allow different attitudes to be expressed and contend with one another and 
true agreement or disagreement to emerge. Each panelist received a summary of the first-round ratings for each measure, including the median, standard error, his/her rating relative to the distribution, and the analytic interpretation. Panelists suggested modifications to definitions of key terms and measures; these were adopted when a majority voted to do so. After all opinions had been voiced for a measure, panelists marked private, equally weighted ballots.

For both rounds, panelists rated validity, feasibility, and importance on 9 -point scales $(9=$ highest). Validity meant: (1) adequate scientific evidence or professional consensus exists to support a link between the performance of care specified by the measure and improved clinical outcomes; and (2) based on the panelists' professional experience, health professionals with significantly higher rates of adherence to a measure would be considered higher-quality providers [13]. Panelists also rated measures for feasibility and importance to facilitate future users' efforts to prioritize the measures. Feasibility meant the potential ability to evaluate adherence to the measure using medical records. Importance meant the magnitude of the potential effect on patient outcomes.

As is standard for this method, ratings interpretations included: valid $=$ a median of 7-9 without disagreement; not valid $=\mathrm{a}$ median of 1-3 without disagreement; uncertain validity $=$ a median of 4-6 or any median with disagreement. Disagreement was defined as three or more panelists rating in the 1-3 range and three or more in the 7-9 range [13]. Measures were considered potentially feasible if the median was 4 or above. There was no minimum threshold for importance because this variable was intended to help future users prioritize the measures.

\section{Comparison with Occupational Medicine Guideline}

An occupational medicine physician assessed how concordant each passing measure was with the current occupational medicine guideline from the American College of Occupational and Environmental Medicine (ACOEM) [24]. Observations were discussed with another physician who also compared the measures and guidelines.

\section{Pilot Testing}

After identifying measures meeting the validity and feasibility criteria, RAND/UCLA team members developed a detailed tool for scoring the measures. For each measure, an experienced research nurse and research associate defined relevant terms within the measures, the populations or care eligible for the measure (the denominator), and instances in which care can be considered to adhere to the measure (the numerator). Timeframes for eligibility and adherence were specified. The team also anticipated feasibility issues, such as data elements that may be difficult to find in medical records or that could require subjective judgments by abstractors, and developed specific instructions to resolve them.

Pilot testing enabled us to examine feasibility issues and preliminary rates of adherence to the measures. Feasibility issues included the ease which relevant patients can be identified, the availability of the medical records required to assess eligibility for and adherence to individual measures, and the clarity and usefulness of the scoring tool. The RAND/UCLA team pilot tested the measures and tool in a large workers' compensation provider organization (Kaiser Permanente Northern California Regional Occupational Health) and in a large workers' compensation insurance company (the California State Compensation Insurance Fund). Six nurses and one physical therapist ("abstractors"), who routinely perform claims reviews within each organization, underwent a two-day training in the use of the tool and scored several practice cases. Finally, they reviewed records for a small sample of patients who had been diagnosed CTS or conditions often confused with CTS. Patients were randomly selected by applying pre-specified criteria (time period and diagnostic category) to administrative databases maintained by the insurance company. The abstractors working for the insurance company reviewed clinical records routinely collected for claims processing. The abstractors working for the provider organization reviewed electronic medical records for each patient. During the training and pilot testing, abstractors provided feedback on the tool. The pilot test activities were approved by each of the institutional human subjects' protection committees; informed consent was not required.

\section{Results}

There were 40 draft measures. During the second round of the rating process, 30 measures were modified, 9 measures did not meet validity criteria, one of these 9 was also judged infeasible, and the remainder passed (31/40 measures passed, $78 \%$ ).

\section{Final Measures}

Nine final RAND/UCLA CTS measures (Table 1) emphasized the initial evaluation of patients with hand and forearm complaints; 11 considered non-operative treatments such as splinting, steroid injections, and other medications; and 11 pertained to addressing activities and functional limitations. 
Table 1 List of quality measures meeting validity and feasibility criteria

Measure title Measure text

Measures for the initial evaluation of hand and forearm symptoms

1. New symptoms characteristic of CTS require detailed assessment

2. New symptoms characteristic of CTS should lead to suspicion

3. New hand or forearm pain requires evaluation for "red flags"

4. Symptoms inconsistent with CTS require evaluation

5. New CTS diagnosis requires assessment of medical risk factors

6. New suspicion of CTS requires specific physical examination

7. New suspicion of CTS requires evaluation for overweight

8. Imaging should be used selectively for suspected CTS

9. Symptoms should be monitored after new diagnosis of CTS

Measures for the non-operative treatment of CTS

10. Splints should be placed in neutral position

11. An attempt at splinting should last at least six weeks

12. NSAIDs should not be used for CTS

13. Muscle Relaxants should not be used for CTS

14. Opioids should not be used for CTS

15. Diuretics should not be used for CTS

16. Steroid treatment requires discussion of risks

17. Discuss benefits of surgery when offering steroids to patients with severe CTS
IF the progress notes document new paresthesias or numbness in the fingers, THEN at least two of the following should be noted at the initial evaluation of those symptoms: (1) a verbal or pictoral description of the location of any pain, numbness, or paresthesias (e.g., Katz hand diagram), (2) the quality of any pain, (3) the duration of any pain, numbness, or paresthesias, (4) onset of pain, numbness, or paresthesias

IF a patient complains of any of the following symptoms: Paresthesias, numbness, or tingling on 1st to 3rd fingers or palm THEN a suspicion of CTS should be documented in the medical record at the initial evaluation of those symptoms.

IF patient complains of new hand or forearm pain THEN the progress notes should document the presence or absence of at least one of the following "Red flags" at the same visit: (1) trauma, (2) deformity, including swelling, (3) fever

IF patient complains of hand or forearm pain and also has any of the following: (1) New fever, (2) New point tenderness, (3) New deformity, THEN at least one diagnosis other than CTS should be evaluated at this visit

IF the progress notes document a new diagnosis of CTS, THEN a history of at least one of the following risk factors should be documented during the first three visits: (1) Rheumatoid arthritis, (2) Diabetes mellitus, (3) Hypothyroidism, (4) Pregnancy, if female, (5) Chronic renal failure

IF the progress notes document that CTS is suspected THEN at least one of the following physical examination maneuvers should be documented at initial evaluation: (1) Testing for sensory abnormalities in median nerve distribution, (2) Testing for thenar muscle weakness, (3) Examination for thenar muscle atrophy

IF the progress notes document that CTS is suspected THEN height and weight, or a clinical judgment about the presence or absence of obesity/overweight, should be documented at initial evaluation

IF the progress notes document that CTS is suspected THEN MRI or ultrasound or CT should not be the initial test for diagnosis unless a structural lesion is suspected

IF patient is newly diagnosed with CTS during a visit THEN at each CTS-related visit during the first three months after presentation, patient should be asked about changes in at least one of the following: (1) Pain or paresthesias in the median nerve distribution, (2) Symptoms of weakness, such as dropping things, decreased grip strength, etc.

IF a patient with CTS is prescribed a splint, THEN the chart should document that the splint was positioned so that the wrist is neutral (neither extension $>10$ degrees or flexed)

IF a patient with CTS is prescribed a neutral splint, THEN the split should be prescribed for at least six weeks

IF a patient is diagnosed with CTS, THEN the patient should not be given NSAIDs to treat CTS symptoms

IF a patient is diagnosed with CTS, THEN the patient should not be given muscle relaxants to treat CTS symptoms

IF a patient is diagnosed with CTS, THEN the patient should not be given opioids to treat CTS symptoms

IF a patient is diagnosed with CTS, THEN the patient should not be given diuretics to treat CTS symptoms

IF a patient with CTS is prescribed oral steroids or administered a steroid injection of the carpal tunnel, THEN the medical record should document that risks of the treatment were discussed

IF a patient has severe CTS, THEN the patient should not be offered a steroid injection or oral steroids without also documentation that the possibility of surgery was discussed 
Table 1 continued

Measure title $\quad$ Measure text

18. Steroids for work-associated symptoms require follow-up

19. Limit steroid injections to 4

20. Lasers should not be used for CTS

\section{Measures for addressing activities and functional limitations potentially associated with CTS symptoms}

21. New CTS diagnosis requires detailed occupational history

22. New CTS diagnosis requires assessment of occupational factors

23. New CTS diagnosis requires assessment of non-occupational factors

24. Exacerbating activities should be identified when CTS limits functioning

25. Rationale for work-association should be documented

26. Patients diagnosed with CTS should be educated about the condition

27. Exposures to vibration, force, and repetition should be minimized

28. Work-associated CTS symptoms require prompt follow-up

29. Work status should be monitored when CTS appears work associated

30. Return to work after CTS-related disability requires follow-up assessment

31. Prolonged CTS-related disability should trigger evaluation
IF steroid injection is performed or oral steroids are prescribed for CTS symptoms that are thought to be work associated THEN physicians should document a follow-up call to or visit with the patient within 4 weeks

IF a steroid injection of the carpal tunnel is performed for CTS, THEN no more than 4 steroid injections should be performed total per hand, unless the provider documents that the patient has refused surgery

IF patients are diagnosed with CTS, THEN low-level laser therapy should not be prescribed for or used in treatment

IF the progress notes document a new diagnosis of CTS, THEN at least one of the following pieces of history should be documented between the time of initial evaluation of the CTS symptoms and the second visit after the diagnosis: (1.) occupation including functional job duties, (2.) duration at given occupation, (3.) whether symptoms improve or worsen at work

IF the progress notes document a new diagnosis of CTS, THEN during the first three visits, the presence or absence of at least one of the following factors should be documented for occupational settings: (1.) mechanical force, (2.) vibration, and (3.) frequent repetitive wrist movements

IF the progress notes document a new diagnosis of CTS, THEN during the first three visits, the presence or absence of at least one of the following factors should be documented for non-occupational settings: (1.) mechanical force, (2.) vibration, and (3.) frequent repetitive wrist movements

IF a patient has a diagnosis of carpal tunnel syndrome and a provider documents that occupational or non-occupational functioning is limited by it THEN the provider should also document the specific job duties or non-occupational activities that are associated with symptoms

IF a patient is diagnosed with CTS and is working outside the home THEN, by the first visit after the initial presentation, the medical record should document the provider's opinion regarding the probability that that the CTS is work associated together with a rationale

IF carpal tunnel syndrome is newly diagnosed THEN within the first four weeks, the provider should document that they educated the patient about at least one of the following: (1.) symptoms; (2.) treatments; (3.) prognosis; (4.) exacerbating factors; (5.) the rationale for a judgment of work-association; (6.) that unnecessary time off work may not benefit the patient; (7.) work-site or work-activity modifications; or (8.) other issues relating to their CTS

IF a patient has a diagnosis of carpal tunnel syndrome and a provider documents exposure to any of the following: mechanical force, vibration, and frequent repetitive wrist movements THEN, during the same visit, the provider should document that they discussed activity modification with the patient

IF a patient has CTS and symptoms are newly thought to be work associated THEN they should be seen for a follow-up visit within 4 weeks of initial evaluation

IF work associated carpal tunnel syndrome is newly diagnosed THEN the provider should document whether or not the individual is currently working at each CTSrelated visit during the first three months

IF a patient diagnosed with CTS returns to work after being on temporary work associated disability for more than four weeks, THEN, within four weeks of returning to work, they should have a follow-up assessment at which the presence or absence of occupational functional limitations is documented

IF a patient is off work for four or more weeks for carpal tunnel symptoms THEN the presence or absence of one of the following: (1.) alcohol or substance abuse, (2.) depression or anxiety, or (3.) other barriers to return to work, should be documented in the medical record by the next visit 
Table 2 lists the title of each measure, validity and feasibility ratings, and the highest level of supporting evidence. For few, if any, of these measures was there a large randomized controlled trial or high-quality observational study directly examining the effect of the care described. Nevertheless, in each instance, there is convincing chain of evidence or clinical rationale that supports the practice. An "Appendix" provides the supporting rationale and a summary of the relevant literature.

\section{Comparison with Occupational Medicine Guideline}

Seventeen measures (55\%) are fully concordant with the ACOEM guideline, five are somewhat concordant (16\%), the ACOEM guideline did not address content within eight of the measures $(26 \%)$, and one measure is discordant with the guideline (3\%) (see Appendix for list) [24]. This last measure addresses the use of non-steroidal anti-inflammatory agents (NSAIDs) for CTS symptoms.

\section{Pilot Testing}

Regarding feasibility issues, the provider organization readily identified eligible patients using ICD-9 and CPT codes and had no difficulty determining eligibility for and adherence to the measures due to the organization's electronic medical record system. However, the insurance company had some difficulty identifying eligible patients because it uses broad diagnostic categories rather than ICD9 and CPT codes, and also assessing eligibility for some measures because its clinical records were incomplete. As to the scoring tool, the research team made many changes based on feedback from the seven abstractors. None of the measures were eliminated due to feasibility concerns.

Regarding preliminary rates of adherence, the pilot study included a total of 28 unique patients. Sixteen had been diagnosed with CTS and 12 with upper extremity disorders commonly confused with CTS. Twenty-four patients were eligible for one or more measures. Care was eligible for a measure a total of 559 times, and adhered to the measures 419 times (an overall adherence rate of $75 \%$ ). Adherence rates were $66 \%$ for initial evaluation, $79 \%$ for non-operative treatment, and $81 \%$ for management of activities and functional limitations. These results illustrate the ability to assess quality of care for CTS and should not be considered representative of the care provided by these organizations.

\section{Discussion}

This paper describes a set of measures that can be used to objectively assess the quality of medical care for carpal tunnel syndrome, with an emphasis on issues specific to occupational settings. The measures address the diagnostic evaluation and non-operative treatment of CTS, including assessing causality and managing occupational activities and functional limitations.

Quality measures that focus on care processes, as these do, are sometimes confused with treatment guidelines because they share development methods and clinical content. However, quality measures and guidelines serve complementary functions (see Table 3). Quality measures are rigid, quantitative tools that distinguish higher and lower quality care after the care has already been provided, whereas guidelines offer information that practitioners may or may not use during real-time clinical decision-making. Measures effectively become mandatory when adherence to them is used to assign penalties or rewards, as payers often do in non-occupational settings. Measures, for this reason, describe basic standards rather than best practices, are silent when the appropriate approaches are uncertain, and are used to assess quality at the population level. Conversely, guidelines are generally designed to be flexible and advisory; therefore, they cannot be accurately or reliably used as quality assessment tools because they permit providers to use their experience when applying recommendations to individual patients and address situations in which there is uncertainty about the preferred approaches. Finally, measures are scored in a systematic, highly structured fashion to ensure consistent results [25]. Thus, although occupational medicine guidelines exist for CTS [24], quality measures are also needed.

As noted in the Introduction, both payors and workers have substantial interests in improving the quality of care for CTS due to the high prevalence and costs associated with the condition. Two studies have demonstrated that quality improvement programs promoting adherence to treatment guidelines can decrease time off work and reduce costs. A randomized controlled trial in Spain demonstrated that improving care for workers with musculoskeletal injuries, including CTS, can markedly affect disability and its costs, saving eleven U.S. dollars per dollar invested [4]. A smaller Washington State program produced similar results: disability costs were reduced by $30 \%$ by improving adherence to treatment protocols and encouraging providers to prescribe activity and plan for return to work [26]. The savings could be even greater if the costs associated with reduced worker productivity were considered, since CTS is a common cause of absenteeism [27]. Thus, improving quality of care for occupational disorders may represent a unique "win-win" for workers and employers, the two central stakeholders in workers' compensation systems.

Efforts to monitor and improve quality of care have already become commonplace in other aspects of the United States healthcare system. Most hospitals are now 
Table 2 Quality measures: measure titles, ratings, and evidence level*

\begin{tabular}{|c|c|c|c|c|c|c|}
\hline \multirow[t]{2}{*}{ Measure title } & \multicolumn{2}{|l|}{ Validity } & \multicolumn{2}{|c|}{ Feasibility } & \multirow{2}{*}{$\begin{array}{l}\text { Importance } \\
\text { Median }\end{array}$} & \multirow{2}{*}{$\begin{array}{l}\text { Evidence } \\
\text { level }^{\dagger}\end{array}$} \\
\hline & Median $^{\dagger}$ & $\begin{array}{l}\mathrm{N}(\%) \text { of } \\
\text { Ratings }>=7\end{array}$ & Median $^{\dagger}$ & $\begin{array}{l}\mathrm{N}(\%) \text { of } \\
\text { Ratings }>=4\end{array}$ & & \\
\hline \multicolumn{7}{|l|}{ Initial evaluation of hand and forearm symptoms } \\
\hline $\begin{array}{l}\text { 1. New symptoms characteristic of CTS require detailed } \\
\text { assessment }\end{array}$ & $8(2-9)$ & $9(82 \%)$ & $8(7-9)$ & $11(100 \%)$ & $8(6-9)$ & 2 \\
\hline 2. New symptoms characteristic of CTS should lead to suspicion & $8(7-9)$ & $11(100 \%)$ & $8(7-9)$ & $11(100 \%)$ & $7(5-8)$ & 2 \\
\hline 3. New hand or forearm pain requires evaluation for "red flags" & $8(1-9)$ & $10(91 \%)$ & $8(1-9)$ & $10(91 \%)$ & $8(1-9)$ & 3 \\
\hline 4. Symptoms inconsistent with CTS require evaluation & $8(6-9)$ & $10(91 \%)$ & $8(4-9)$ & $11(100 \%)$ & $8(5-9)$ & 3 \\
\hline 5. New CTS diagnosis requires assessment of medical risk factors & $8(1-9)$ & $9(82 \%)$ & $8(7-9)$ & $11(100 \%)$ & $8(5-9)$ & 3 \\
\hline 6. New suspicion of CTS requires specific physical examination & $8(5-9)$ & $10(91 \%)$ & $8(4-9)$ & $11(100 \%)$ & $8(5-9)$ & 2 \\
\hline 7. New suspicion of CTS requires evaluation for overweight & $7(5-9)$ & $9(82 \%)$ & $7(7-9)$ & $11(100 \%)$ & $6(2-9)$ & 3 \\
\hline 8. Imaging should be used selectively for suspected CTS & $8(7-9)$ & $11(100 \%)$ & $8(8-9)$ & $11(100 \%)$ & $7(3-9)$ & 3 \\
\hline 9. Symptoms should be monitored after new diagnosis of CTS & $8(7-8)$ & $11(100 \%)$ & $8(7-9)$ & $11(100 \%)$ & $7(4-8)$ & 3 \\
\hline \multicolumn{7}{|l|}{ Non-operative treatment of CTS } \\
\hline 10. Splints should be placed in neutral position & $8(7-9)$ & $11(100 \%)$ & $8(5-9)$ & $11(100 \%)$ & $7(4-9)$ & 1 \\
\hline 11. An attempt at splinting should last at least six weeks & $7(1-8)$ & $8(73 \%)$ & $7(1-8)$ & $11(100 \%)$ & $7(1-8)$ & 1 \\
\hline \multicolumn{7}{|l|}{ Certain medications should not be used for CTS } \\
\hline 12. NSAIDs & $7(4-8)$ & $9(82 \%)$ & $7(6-9)$ & $11(100 \%)$ & $7(3-9)$ & 1 \\
\hline 13. Muscle Relaxants & $7(6-9)$ & $10(91 \%)$ & $8(6-9)$ & $11(100 \%)$ & $7(3-9)$ & 3 \\
\hline 14. Opioids & $8(7-9)$ & $11(100 \%)$ & $8(7-9)$ & $11(100 \%)$ & $7(3-9)$ & 3 \\
\hline 15. Diuretics & $8(2-9)$ & $11(100 \%)$ & $8(7-9)$ & $11(100 \%)$ & $7(2-9)$ & 1 \\
\hline 16. Lasers should not be used for CTS & $8(7-9)$ & $11(100 \%)$ & $8(3-9)$ & $10(91 \%)$ & $7(1-9)$ & 1 \\
\hline $\begin{array}{l}\text { 17. Discuss benefits of surgery when offering steroids to patients } \\
\text { with severe CTS }\end{array}$ & $8(6-8)$ & $10(91 \%)$ & $8(6-9)$ & $11(100 \%)$ & $8(5-8)$ & 1 \\
\hline 18. Steroid treatment requires discussion of risks & $8(6-9)$ & $10(91 \%)$ & $8(7-9)$ & $11(100 \%)$ & $6(3-9)$ & 3 \\
\hline 19. Steroids for work-associated symptoms require follow-up & $7(6-9)$ & $10(91 \%)$ & $8(7-9)$ & $11(100 \%)$ & $7(5-9)$ & 3 \\
\hline 20. Limit steroid injections to 4 & $7(4-9)$ & $10(91 \%)$ & $8(5-9)$ & $11(100 \%)$ & $7(3-9)$ & 3 \\
\hline \multicolumn{7}{|c|}{ Addressing activities and functional limitations potentially associated with CTS symptoms } \\
\hline 21. New CTS diagnosis requires detailed occupational history & $7(2-9)$ & $9(82 \%)$ & $7(7-9)$ & $11(100 \%)$ & $6(2-9)$ & 3 \\
\hline $\begin{array}{l}\text { 22. New CTS diagnosis requires assessment of occupational } \\
\text { factors }\end{array}$ & $7(5-9)$ & $8(73 \%)$ & $8(5-9)$ & $11(100 \%)$ & $7(5-9)$ & 2 \\
\hline $\begin{array}{l}\text { 23. New CTS diagnosis requires assessment of non-occupational } \\
\text { factors }\end{array}$ & $7(5-9)$ & $8(73 \%)$ & $8(5-9)$ & $11(100 \%)$ & $7(5-9)$ & 2 \\
\hline $\begin{array}{l}\text { 24. Exacerbating activities should be identified when CTS limits } \\
\text { functioning }\end{array}$ & $7(4-9)$ & $6(55 \%)$ & $7(6-9)$ & $11(100 \%)$ & $7(5-9)$ & 3 \\
\hline 25. Rationale for work-association should be documented & $7(4-8)$ & $6(55 \%)$ & $6(3-8)$ & $9(82 \%)$ & $7(4-9)$ & 3 \\
\hline $\begin{array}{l}\text { 26. Patients diagnosed with CTS should be educated about the } \\
\text { condition }\end{array}$ & $7(5-9)$ & $6(55 \%)$ & $7(4-9)$ & $11(100 \%)$ & $7(5-9)$ & 3 \\
\hline $\begin{array}{l}\text { 27. Exposures to vibration, force, and repetition should be } \\
\text { minimized }\end{array}$ & $7(3-9)$ & $7(64 \%)$ & $7(4-8)$ & $11(100 \%)$ & $7(4-9)$ & $2-3$ \\
\hline 28. Work-associated CTS symptoms require prompt follow-up & $8(6-9)$ & $10(91 \%)$ & $8(5-9)$ & $11(100 \%)$ & $8(2-9)$ & 3 \\
\hline $\begin{array}{l}\text { 29. Work status should be monitored when CTS appears work } \\
\text { associated }\end{array}$ & $7(5-9)$ & $9(82 \%)$ & $7(5-9)$ & $11(100 \%)$ & $7(5-9)$ & 3 \\
\hline $\begin{array}{l}\text { 30. Return to work after CTS-related disability requires follow-up } \\
\text { assessment }\end{array}$ & $7(5-9)$ & $6(55 \%)$ & $7(6-9)$ & $11(100 \%)$ & $6(5-9)$ & 3 \\
\hline 31. Prolonged CTS-related disability should trigger evaluation & $7(6-9)$ & $10(91 \%)$ & $7(6-9)$ & $11(100 \%)$ & $7(6-9)$ & $2-3$ \\
\hline
\end{tabular}

* The table lists measure titles. The actual text of the measures is provided in Table 1

$\dagger$ Validity Ratings $>=7$ indicated panelists thought the measure was valid. Feasibility Ratings $>=4$ indicated panelists thought the measure was potentially feasible. Level of Evidence: $1=$ randomized controlled trial, $2=$ observational data, $3=$ case series or expert consensus 
Table 3 Similarities and differences between process-oriented quality measures and clinical treatment guidelines

\begin{tabular}{|c|c|c|}
\hline & Process-oriented quality measures & Clinical treatment guidelines \\
\hline Definition & $\begin{array}{l}\text { Criteria used to evaluate components of an encounter } \\
\text { between a physician or another health care } \\
\text { professional and a patient, and for which variations in } \\
\text { adherence lead to differences in outcomes[36] }\end{array}$ & $\begin{array}{l}\text { Systematically developed statements that assist } \\
\text { practitioner and patient decisions about } \\
\text { appropriate health care for specific clinical } \\
\text { circumstances [37] }\end{array}$ \\
\hline Developers & $\begin{array}{l}\text { Non-profit entities, government bodies, specialty } \\
\text { societies, researchers, payers }\end{array}$ & $\begin{array}{l}\text { Non-profit entities, government bodies, specialty } \\
\text { societies, researchers, payers }\end{array}$ \\
\hline Development methods & $\begin{array}{l}\text { Systematic literature reviews coupled with work by } \\
\text { expert panels }\end{array}$ & $\begin{array}{l}\text { Systematic literature reviews coupled with work by } \\
\text { expert panels }\end{array}$ \\
\hline $\begin{array}{l}\text { Proprietary or publicly } \\
\text { available }\end{array}$ & Either & Either \\
\hline Specifies basic standards & Yes & Yes \\
\hline Specifies best practices & No & Yes \\
\hline $\begin{array}{l}\text { Discusses areas } \\
\text { of uncertainty }\end{array}$ & No & Yes \\
\hline Mandatory or advisory & $\begin{array}{l}\text { Effectively mandatory when used as a basis for } \\
\text { assigning rewards and penalties [25] }\end{array}$ & Advisory [25] \\
\hline Rigid or flexible & $\begin{array}{l}\text { Rigid. Focus on selected situations for which there are } \\
\text { clear "right" or "wrong" approaches [25] }\end{array}$ & $\begin{array}{l}\text { Very flexible, intended to inform provider } \\
\text { judgments and patient preferences [25] }\end{array}$ \\
\hline Length & $\begin{array}{l}\text { Measures are very concise and precisely written } \\
\text { statements }(1-2 \text { sentences })\end{array}$ & $\begin{array}{l}\text { Guidelines can be long documents that include } \\
\text { details about development methods, systems for } \\
\text { classifying the evidence, summaries of research } \\
\text { evidence, rationales for consensus-based } \\
\text { recommendations, etc. }\end{array}$ \\
\hline $\begin{array}{l}\text { Supporting } \\
\text { documentation }\end{array}$ & $\begin{array}{l}\text { Often extensive to ensure consistent interpretation of } \\
\text { the measures. Defines relevant terms, population } \\
\text { eligible for the measure, conditions for satisfying the } \\
\text { measure, instructions for interpreting the often } \\
\text { variable information in clinical data sources, etc. }\end{array}$ & Not needed. \\
\hline Users & $\begin{array}{l}\text { Generally used by organizations (large provider } \\
\text { organizations or payers), researchers, or } \\
\text { representatives of government. Can be used by } \\
\text { individual providers for self-assessment, such as } \\
\text { during board recertification activities }\end{array}$ & $\begin{array}{l}\text { Generally designed to be used by individual } \\
\text { providers }\end{array}$ \\
\hline Timing of use & Generally after care has been provided (retrospective) & Generally at the point of care (concurrent) \\
\hline Target population & $\begin{array}{l}\text { Carefully defined populations of patients relevant to } \\
\text { individual measures or sets of measures }\end{array}$ & $\begin{array}{l}\text { Patients in a broad category defined by the } \\
\text { possibility that they may have or develop a } \\
\text { particular condition, or may be a candidate for a } \\
\text { particular treatment }\end{array}$ \\
\hline $\begin{array}{l}\text { Use is systematic } \\
\text { or ad hoc }\end{array}$ & $\begin{array}{l}\text { Highly systematic scoring of adherence to criteria. } \\
\text { Often used to assess care for a population or sample } \\
\text { thereof. }\end{array}$ & $\begin{array}{l}\text { Ad hoc, not scored. Used to look up specific } \\
\text { questions as they arise. }\end{array}$ \\
\hline $\begin{array}{l}\text { Prevalence of use } \\
\text { in U.S. Healthcare } \\
\text { system }\end{array}$ & $\begin{array}{l}\text { Ninety percent of health plans for non-occupational } \\
\text { settings participate in the HEDIS program [29]. } \\
\text { Medicare assesses quality of care for all hospitals and } \\
\text { nursing homes [28]. Quality measures are used in } \\
\text { multiple other efforts to improve quality of care } \\
\text { nationally. }\end{array}$ & $\begin{array}{l}\text { Physicians do not consistently incorporate clinical } \\
\text { guidelines into their decision making because of } \\
\text { lack of knowledge, barriers to guideline } \\
\text { implementation, and unfavorable attitudes toward } \\
\text { guidelines [38] }\end{array}$ \\
\hline
\end{tabular}

required to publicly report performance with regards to acute myocardial infarction, heart failure, and pneumonia [28]. The National Committee on Quality Assurance's Healthcare Effectiveness Data and Information Set (HEDIS) enables health plans to monitor and report the quality of the care their enrollees receive. Because $90 \%$ of health plans participate in the HEDIS program and employers consider HEDIS scores in healthcare purchasing decisions [29], health plans have financial incentive to improve quality of care. Comparable efforts to assess and improve 
care could be undertaken for occupationally associated disorders.

Provider organizations, payors, and others planning to use these measures will need detailed specifications to score them consistently. The research team has developed and pilot tested a comprehensive scoring tool that will support these efforts. This tool includes all of the measures, including those pertaining to electrodiagnosis and surgery. RAND will make the refined, final tool available for free on its website during the summer of 2010. Provider organizations may be in a better position to identify eligible patients and assess quality than payors are. We found this to be the case in our pilot study. Further, in non-occupational settings, providers typically perform these functions and report quality of care data to payers (with oversight and validation activities to ensure the integrity of the data).

\section{Comparison with Occupational Medicine Guideline}

Overall, we found substantial concordance between the RAND/UCLA CTS measures and the ACOEM guideline, a major occupational medicine guideline, although there are notable differences. The RAND/UCLA measures disapprove of NSAIDs for CTS because a randomized controlled trial showed no benefits and these medications increase the risks of gastrointestinal bleeding and myocardial infarction [30, 31], whereas the ACOEM guideline considers NSAIDs to be an appropriate option. Also, the ACOEM guideline addresses many important topics that, for reasons discussed above, the measures omit.

For example, no measure defines the optimal method for establishing a diagnosis of CTS. Many studies, guidelines, and commentators have wrestled with this issue. Certain approaches to history taking and physical examination have higher specificities for CTS, using positive electrodiagnostic tests as the gold standard. In turn, positive electrodiagnostic tests increase the probability that patients will respond to surgery [15]. However, as of yet, there appears to be no clear consensus as to the "correct" approach to synthesizing this information into a clinical diagnosis. Consequently, the quality measures address the diagnostic evaluation for CTS, but not the diagnosis itself.

While the ACOEM guideline will be useful for informing providers of the preferred means of caring for patients with occupational CTS, the RAND/UCLA measures can be used to assess quality of care and monitor the effectiveness of any improvement efforts. Individual providers can use these measures to evaluate the quality of the care they provide. Periodic retrospective chart review is a central component of the occupational and preventive medicine maintenance-of-certification processes [32, 33].
The RAND/UCLA CTS measures could be used in such reviews. Practices with multiple providers can evaluate quality for the practice and, if warranted, develop an infrastructure that supports improvement. Organizational efforts are particularly likely to be effective because they leverage the contributions of many individuals, and they enable systems to be established that make adherence simpler. Finally, payors of compensation claims might consider using these measures as a basis for referring patients to higher-quality providers, or as a basis for offering higher-quality providers greater remuneration.

\section{Limitations}

Quality measures do have limitations. Some important aspects of care for patients with CTS are not amenable to measurement. For example, patients can be sensitive about discussing potential barriers to returning to work, such as conflicts with supervisors, and some providers may conduct these discussions more effectively than others do. But many important aspects of care can be measured. Also, for each measure, unique clinical circumstances will warrant exceptions to the rule. Justifiable exceptions are not problematical so long as sample sizes are sufficient and exceptions are rare and randomly distributed among populations of patients.

These measures also have specific limitations. First, the literature examining these practices is rather limited, and most of the measures are based on expert consensus. Musculoskeletal disorders suffer for a lack of large, highquality randomized controlled trials, and randomized controlled trials are not feasible for all aspects of care. In the past, this panel method has successfully overcome similar limitations to the literature for osteoarthritis, rheumatoid arthritis, arthroplasty of the knee and hip, and many other clinical situations $[18,34,35]$. Second, the panel included a higher proportion of surgeons than it would have if only diagnosis and non-operative treatment were considered. To mitigate this issue, we submitted the measures for each topic to relevant subspeciality journals in occupational medicine, neurology, and surgery, thereby ensuring that the measures undergo peer review by experts in these respective disciplines.

Third, the ultimate test of measures' validity entails assessing whether better adherence is associated with better patient outcomes. In September 2010, we are planning to undertake a prospective study that will compare adherence to these measures with patients' symptoms, functional status, time off work, and permanent disability ratings. We expect to find an association because associations have been found for previous sets of measures developed using the same methods. However, most quality measures in wide use today have yet to be been tested in this fashion. 
In conclusion, this project has developed 31 measures that can be used to evaluate the quality of the care for CTS. These measures appear to be the first quality measures to address both medical and occupational issues; therefore, they lay the groundwork for quality assessment activities to be introduced in occupational settings. These measures could be useful in a variety of efforts to improve quality of care for patients with CTS, whether initiated by providers, medical groups, payors, or policymakers. Similar measures should be developed for other workassociated disorders.

Acknowledgments Christine Baker, MS, Executive Director of the California Commission on Health and Safety and Workers' Compensation, made this project possible. We are grateful to the members of the project Advisory Board: D. Lachlan Taylor, J.D. (Workers' Compensation Judge, Commission on Health \& Safety and Workers' Compensation), Gideon Letz, MD (Medical Director, California State Compensation Fund), Bernyce Peplowski, MD (Medical Director, Zenith Insurance), Kathryn Mueller MD, MPH (Professor, University of Colorado and Medical Director for the Colorado Division of Workers' Compensation), Jane Dereberry, MD (previously with Concentra Occupational Health Research Institute, Austin, TX). Two of the co-authors on the paper (PH and DB) are Occupational Medicine specialists, were members of the Advisory Board, and played major roles in the research. We are also grateful to the following individuals for assistance with pilot testing the measures: Steven Black, Alverna Bautista, Nonie Devens, and Patti A. Heaps (all with Kaiser Permanente Regional Occupational Health of Northern California) and Mary Cassidy (with the California State Compensation Insurance Fund). RAND staff member Krasimir Karamfilov provided assistance with the research.

Grants This project was jointly supported through a contract with the California Commission on Health and Safety and Workers' Compensation (CHSWC) and a project-directed gift from Zenith Insurance. CHSWC is a State-sponsored joint labor-management body charged with overseeing the health and safety and workers' compensation systems in California and recommending administrative or legislative modifications to improve their operation. Zenith Insurance is a workers' compensation insurance company based in Woodland Hills, California. The RAND/UCLA team was wholly responsible for the design and execution of this study, including the development of draft measures, selecting panelists, convening the panel, analyzing results, and preparing manuscripts for journal submission. The funding sources played no role in these activities. We instituted several precautions to prevent the source of funding from influencing the research: (1) the work was conceived of and developed by the researchers well before Zenith Insurance provided funding, (2) a minority of the funding came from Zenith Insurance, (3) Zenith Insurance provided the funding as a gift without condition, (4) neither funder played any role in the development and selection of the draft measures, (5) neither played any role in the expert panel's analysis of the measures or the researchers' analysis of the panelists' ratings, and (6) neither played any role in the interpretation of results or drafting of the manuscript (indeed, they never even provided comments on it).

Open Access This article is distributed under the terms of the Creative Commons Attribution Noncommercial License which permits any noncommercial use, distribution, and reproduction in any medium, provided the original author(s) and source are credited.

\section{Appendix: List of Measures, Rationales, and Summaries of Relevant Literature}

\author{
Quality Measures for Initial Evaluation of Hand \\ and Forearm Symptoms
}

\section{History}

The history plays a key role in assisting practitioners to make a correct diagnosis. Although data relating specific pieces of the history to improved patient outcomes is relatively limited, there are key components of the history that help to narrow the differential diagnosis and point toward or away from CTS. Typically, patients with CTS have symptoms of paresthesia and pain [39, 40]. Stevens et al. [39]. identified 100 patients with symptomatic electrodiagnostically confirmed CTS (159 hands) and found that the vast majority of them reported paresthesias $(78,93$, and $96 \%$ in the thumb, index and middle finger respectively). Forty percent of them reported having pain in the hands [39]. Other important pieces of history that have been identified include the location of the pain, quality, duration, and onset [41-45].

The Katz hand diagram is a self-administered diagram where patients mark symptoms including pain, numbness, tingling and decreased sensation. By comparing the patient's diagram against a classification system for symptoms, physicians then determine whether the symptoms reflect classic, probable, possible or unlikely CTS. In a cohort study, sensitivity was $80 \%$ and specificity was $90 \%$ compared to CTS as defined by nerve conduction studies, unequivocal response to corticosteroid injection or improvement in symptoms after surgical release [44]. Subsequent reviews have concluded that the Katz hand diagram is among the better diagnostic tests for CTS [46, 47].

Because CTS is commonly confused with other conditions that cause symptoms in the hand and forearm and an incorrect diagnosis can lead to delays in treatment [48], panelists felt that providers must recognize symptoms that may represent CTS early on. CTS is most probable when symptoms occur in the first through third digits or on the palm in the area of the thenar eminence [46].

Asking about and documenting "red flags," including history of trauma, deformity and fever, assists with making a diagnosis. Because such historical information is inconsistent with CTS, their presence necessitates an investigation of other conditions. These elements of care are recommended by the American College of Occupational and Environmental Medicine Guidelines [49].

Asking patients about activities associated with CTS symptoms enables any exacerbating factors to be identified and mitigated; this is discussed in the section below. In addition, providers should ask patients whether they have 
certain systemic diseases that are risk factors for CTS because identifying the underlying disease may direct therapy to improve CTS symptoms in some patients. Nonoccupational risk factors include connective tissue disease (like rheumatoid arthritis), diabetes, hypothyroidism, osteoarthritis of the wrist and carpal bones, and pregnancy. History of wrist fracture is also strongly associated with CTS, and identification of this risk factor would help focus treatment on correction of anatomic changes that may be causing CTS [50-54].

\section{Physical Examination}

Although providers employ many physical examination findings and tests to evaluate for CTS, the current panelists believed that an adequate physical examination would include at least one of the following: assessing thenar muscle strength, assessing sensibility in the median nerve distribution, and checking for thenar muscle atrophy.

Reviews have identified thumb abduction testing and testing for decreased sensitivity to pain in the median nerve territory compared with ipsilateral ulnar nerve territory, as having among the strongest evidence as good diagnostic tests [46, 47]. Thumb abduction was tested by Kuhlman et al. and found to have sensitivity and specificity of $66 \%$ and de Krom et al. found a sensitivity of $39 \%$ and specificity of $80 \%$ as compared to nerve conduction studies for the diagnosis of CTS [47, 53]. Testing for median nerve territory hypalgesia was evaluated by Golding et al. [55].; it had a low sensitivity of $15 \%$ but a good specificity of $93 \%$ as compared to nerve conduction studies [55]. Kuhlman et al. demonstrated a sensitivity of $51 \%$ and specificity of $85 \%$ as compared to nerve conduction studies [47]. Pooling the results of the last 2 studies produced a positive likelihood ratio of 31 (95\% confidence interval 2.0-5.1) and negative likelihood ratio 0.7 (95\% confidence interval 0.5-1.1). In contrast, widely performed tests like Phalen's and Tinel's actually have poor ability to predict the diagnosis of CTS as defined by nerve conduction studies [46]. Given studies evaluating the various maneuvers are somewhat limited, the panelists felt that any maneuvers assess thenar muscle strength and sensibility in the median nerve territory would be acceptable.

Thenar atrophy is not particularly sensitive or specific for CTS but it is important to document because it is a marker for more severe CTS. Indeed, our panelists defined severe carpal tunnel syndrome by the presence of thenar atrophy. Many surgeons consider the presence of thenar weakness or atrophy to be an indication for a surgical release. For example, new treatment guidelines from the American Academy of Orthopedic surgeons consider early surgery an option when patients have clinical evidence of median nerve denervation [56]. Studies are equivocal on whether this finding is with worse outcomes following carpal tunnel release [57-59].

In addition to the above physical examination maneuvers of the hand and wrist itself, determining whether the patient may be overweight or obese is important because several articles have linked increased body mass index with CTS $[50,60]$.

\section{Imaging}

Because nerve conduction studies have high degree of sensitivity and specificity for the diagnosis of CTS if performed per the American Association of Electrodiagnostic Medicine guidelines, they should be the primary test to assist with the diagnosis of CTS. Radiographs, MRI, and $\mathrm{CT}$ can be considered if space-occupying lesions or fractures are suspected; existing literature does not support the routine use of imaging tests for patients with CTS [41, 61, $62]$.

\section{Follow-up}

Panelists concluded that, during any follow-up visit in the three months after CTS is diagnosed, when symptoms and functional status are undergoing the most changes [63], patients should be asked about symptoms of pain, paresthesias and weakness in the median nerve distribution in order to assess how the patient is doing compared with their initial presentation. A significant proportion of patients treated with conservative therapy (non-surgical treatments) will progress and may need surgery [64-66]. They did not stipulate when follow-up visits must occur for patients without work-associated CTS; work-associated CTS is discussed below.

\section{Quality Measures for Non-Operative Treatment}

Splinting A poorly made, positioned, or used splint can cause more problems than it solves. While many pre-fabricated splints come out of the box in a position of 20-30 degrees of wrist extension, this is not the position preferred for immobilization of the carpal tunnel structures. The provider must fabricate or reposition the splint to neutral. Use of a wrist splint in extension actually increases pressure within the carpal tunnel relative to use of splints in a neutral position [67].

Use of the splint for at least six weeks (or as long as symptoms persist) improves outcome (decreased pain, improved function) compared with less persistent, more intermittent use. Two randomized, controlled trials have examined the effectiveness of splinting and the timing of use associated with improvement. Werner randomized 112 autoworkers with possible, probable, and definite carpal 
tunnel syndrome (based upon presence of tingling, burning or pain in the distribution of the median nerve from hand diagram score) to treatment with ergonomic education alone or custom wrist splint worn at night for six weeks [68]. The splinted group had a significant reduction in wrist, hand, and/or finger discomfort and improvement in the Levine symptom severity scale. In a randomized study, Walker et.al. studied 30 hands of 21 veterans with electrodiagnostic demonstrated carpal tunnel syndrome and compared night-only versus full-time use of custom neutral wrist splint. The full-time use group reported more improvement than the overnight group on the Levine symptom severity scale, and such improvement was also noted in improved sensory distal latency in the full-time group [69].

\section{Medications}

The panelists concluded that diuretics, NSAIDs, opioids, and muscle relaxants are inappropriate therapies for CTS symptoms. Diuretics and NSAIDs provide no symptomatic relief to patients with CTS compared with placebo. Chang et.al. evaluated 73 patients with mild to moderate carpal tunnel syndrome confirmed electrodiagnostically and randomized them to receive placebo, a diuretic (trichlormethiozaide), an NSAID (tenoxicam-SR) or oral steroids (prednisolone) for four weeks. Patients who received diuretics, NSAIDs, or placebo had no change in their symptoms relative to baseline [70]. Given these findings and the risks of gastrointestinal bleeding and myocardial infarction, the risks of using NSAIDs outweigh the potential benefits for carpal tunnel syndrome [71]. There is no evidence that opioids, or muscle relaxants relieve carpal tunnel syndrome symptoms and the panelists noted that they too may harm patients.

Several studies demonstrate that locally injected or oral steroids appear to benefit patients with carpal tunnel syndrome [64, 70, 72-74]. One randomized, controlled trial demonstrated the two delivery modalities have similar efficacy [74]. However, due to the attendant risks of each, the panelists felt that offering these treatments to patients should be optional, not mandatory. Further, for all patients offered steroids, a full discussion of the benefits and risks of the steroid injections should occur prior to proceeding because the patient should be actively involved in his or her care. The principle of informed consent relies on the patient's full understanding of benefits and risks of any medical treatment prior to it undertaking. Although the risks are not common, they include median nerve injury, (digital flexor) tendon rupture, bleeding, infection, and reflex sympathetic dystrophy $[75,76]$.

For patients with severe CTS, a randomized, controlled trial demonstrated that steroid injections do not have lasting benefits and surgery is more effective. Thus providers should discuss the possibility of surgery as an alternative to steroid injections. Gelberman et al. demonstrated that for patient with severe CTS, only 4 patients out of 32 had complete relief of symptoms at 18 months after steroid injection as compared with 7 out of 18 in the mild to moderate CTS group [77]. A more recent study demonstrates that outcomes are superior with release than with splinting [78]. The data on whether steroid injections or surgery is superior in improving CTS symptoms among patients without thenar atrophy is conflicting [75, 79].

If a patient does receive steroids either orally or via injection, a physician should call or see the patient to inquire about adverse effects and any response to treatment. If the patient notes no improvement, reassessment of whether the initial diagnosis was correct or consideration of other therapies is warranted. The panelist felt that such contacts with patients are generally recommended, but that they are essential when the CTS appears work-associated (i.e., the symptoms worsen during or after work) and that the follow-up contact should occur no later than 4 weeks after the initiation of treatment.

Steroid injections are not without risk and multiple repeated injections are less likely to confer benefit. Wong et al. randomized 40 patients to either to single steroid injection or 2 steroid injections 8 weeks apart. At 10 months, there were no differences in symptoms between the two groups [80]. Per the Quality Standards Subcommittee of Academy of Neurology, no more than 3 steroid injections should be attempted [41]. The current panel felt that the maximum number that would be acceptable was four, which allows for additional extenuating circumstances for some patients.

\section{Lasers}

A randomized controlled trial has demonstrated that lowlevel lasers are not effective in decreasing symptoms in patients with CTS [81].

Quality Measures for Addressing Associated Activities and Functional Limitations Potentially Associated with CTS Symptoms

There are two basic reasons that patients with CTS may need to change their activities at work or at home. First, some activities can exacerbate the CTS symptoms. Second, CTS, or its treatment, may lead to functional limitations, defined as any major activities the patient cannot do now but could do before the CTS symptoms started. Both an association with symptoms and functional limitations can create the need for patients to completely eliminate certain activities ("activity restriction"), or to modify how they 
perform them ("activity modification"). Occupational activity restrictions can be achieved either by eliminating the specific job tasks involving those inciting factors or, if necessary, by placing the individual on disability. Activity modifications can permit an individual to more safely perform a task that involves exposure to a known inciting factor Both occupational and non-occupational activities are important because all exposures to inciting factors need to be identified and mitigated, and because CTS can adversely affect functioning in both occupational and nonoccupational settings $[82,83]$.

\section{History of Associated Activities and Functional Limitations}

Asking patients with CTS symptoms about the nature of their occupation is important so that high risk occupations and tasks can be identified, and job modifications can be implemented. For example, occupations associated with higher prevalence of CTS include electrical assembly, food packing and processing, frozen food packaging, and poultry workers, among others [84]. Detailed information on the patient's functional job duties, duration of current employment, and the timing of the symptoms relative to work activities are important to determining whether a workers' compensation claim may be appropriate. The panelists felt that a minimum standard of care included documenting one of these pieces of occupational information.

Of the many factors that researchers have examined for an association with CTS, mechanical force, vibration, frequent repetitive movements or some combination of the three appear to be most strongly associated [84-86]. Silverstein et al. evaluated 652 industry workers (in 39 different jobs from seven industrial sites) and categorized their work as by force and repetitiveness and screened them for CTS by symptoms and physical exam. They found that high repetitiveness was a risk factor for CTS and the combination of high force and high repetitiveness also increased risk for CTS [87]. Cannon et al. in a case control study, found that use of vibratory tools was associated with CTS with an odds ratio of 13.8 [88]. The panelists concluded that a minimum standard of care entailed assessing whether any such exposures are present for both occupational and non-occupational settings, since people may engage in hobbies, sports, or other non-employment-related activities that exacerbate CTS symptoms.

In addition to associated activities, functional limitations are also important because they are symptoms that reflect the severity of the condition and how well patients are responding to therapy $[82,83]$. Limitations can be occupational, such as an inability to perform specific job tasks[82, 83]; or non-occupational, such as difficulties turning keys, opening jars, buttoning clothes, etc. [89-91]. When limitations are present, the specific nature of the limitations must be understood in order to formulate recommendations for modifying activities and to monitor responses to therapy over time. The panelists concluded that a basic standard of care is for providers to document the specific functional job duties or non-occupational activities that the patients cannot perform.

\section{Judgments of Work Association}

Assessing and documenting the likelihood that CTS is work associated is not only consistent with the expectations of State and Federal governments but also benefits patients [92-94]. Individuals with work-related CTS are entitled to medical benefits under workers' compensation systems. If a treating healthcare professional does not assess whether an individual patient's CTS is work-related, then that provider would be less likely to recognize when a workers' compensation claim is appropriate. Administrative delays occur when treating healthcare professionals fail to make judgments about causation, or fail to provide a rationale for the judgments. Such delays can prevent patients from receiving necessary care in a timely fashion, which can prolong their CTS symptoms [95]. Thus, healthcare professionals treating patients with CTS have a basic responsibility to document their opinion as to the likelihood that the CTS is work-related together with a rationale. Several prior panels have come to this conclusion, as did the current panel $[49,96,97]$.

\section{Patient Education and Activity Modification}

Patient education is an important component of any therapeutic treatment plan because it supports patient adherence to provider recommendations, helps patients to navigate the healthcare and workers' compensation systems, and enables patients to play a more active role in managing their recovery. This assertion is supported by the fact that patients' confidence in their ability to function despite having CTS was a significant predictor of return to work and work-role functioning in the studies described above $[98,99]$. As with any condition, patients should be provided with basic information about common symptoms and treatments as well as prognosis. In addition, patients with CTS should be advised to avoid well-established inciting factors; such as vibration, mechanical force, frequent repetitive movements, and awkward postures; since such exposures are common in occupational and nonoccupational settings [86]. An American College of Occupational and Environmental Medicine position statement makes several recommendations regarding workassociated CTS [100]. When providers judge CTS to be work-associated, patients need to understand the rationale 
since they are entitled to file a workers' compensation claim and will need this information to navigate the workers' compensation system. Since patients may not realize that unnecessary time off work is often not in their best interest, they should be apprised of this. When work-site or workactivity modifications are recommended, providers should make it clear that patients are responsible for communicating these recommendations to their employers. Lastly, when patients are well enough to safely return to work, they should be informed of this. The current panelists recognized that each of these types of education is helpful, and felt it is essential that some patient education occur. When an exposure to vibration, mechanical force, or frequent repetitive movements is present, panelists felt that patients must be instructed in modifying their activities to avoid the exposure.

\section{Follow-up}

The current panelists concluded that follow-up must occur promptly for patients with work-associated CTS. Although no studies have directly evaluated the effect of having regular follow-up on patient outcomes, several guidelines have made recommendations, which vary from every 3-5 days [49], to every two weeks [97], to at least once within six months [41]. The current panel considered follow-up within four weeks of the initial evaluation to be a minimum standard of care applicable to all patients with work-associated CTS (including those not off work).

During the first three months after CTS is diagnosed, when disability and functional status undergo the greatest changes [63], it is essential for providers to document whether or not patients are working. For patients who are on temporary disability, documenting that they have not yet returned to work is necessary in order to determine when returning would be appropriate. Among patients who are not placed on disability, monitoring work status is an important component of monitoring functional status, and is part of monitoring exposure to any occupational inciting factors.

After individuals with CTS return to work following a prolonged period of temporary disability, their CTS needs to be reassessed [97]. The current panel concluded that, at a minimum, providers should also document whether the patient is experiencing any functional limitations at their place of work, so that treatments or job tasks can be modified, if necessary.

Table 4 Comparison of RAND/UCLA CTS quality-of-care measures with the ACOEM guideline [49]

\begin{tabular}{|c|c|c|}
\hline RAND/UCLA measure title & $\begin{array}{l}\text { Concordance with } \\
\text { ACOEM guideline }\end{array}$ & Comments \\
\hline $\begin{array}{l}\text { 1. New symptoms characteristic of CTS require } \\
\text { detailed assessment }\end{array}$ & Concordant & \\
\hline $\begin{array}{l}\text { 2. New symptoms characteristic of CTS should lead } \\
\text { to suspicion }\end{array}$ & Concordant & \\
\hline $\begin{array}{l}\text { 3. New hand or forearm pain requires evaluation for } \\
\text { "red flags" }\end{array}$ & Concordant & \\
\hline $\begin{array}{l}\text { 4. Symptoms inconsistent with CTS require } \\
\text { evaluation }\end{array}$ & Concordant & $\begin{array}{l}\text { Some relevant content is in guideline sections that } \\
\text { are not specific to CTS. }\end{array}$ \\
\hline $\begin{array}{l}\text { 5. New CTS diagnosis requires assessment of } \\
\text { medical risk factors }\end{array}$ & Concordant & \\
\hline $\begin{array}{l}\text { 6. New suspicion of CTS requires specific physical } \\
\text { examination }\end{array}$ & Concordant & \\
\hline $\begin{array}{l}\text { 7. New suspicion of CTS requires evaluation for } \\
\text { overweight }\end{array}$ & Not Addressed (N/A) & $\begin{array}{l}\text { Guideline does not explicitly link overweight/ } \\
\text { obesity and CTS. }\end{array}$ \\
\hline $\begin{array}{l}\text { 8. Imaging should be used selectively for suspected } \\
\text { CTS }\end{array}$ & Concordant & \\
\hline $\begin{array}{l}\text { 9. Symptoms should be monitored after new } \\
\text { diagnosis of CTS }\end{array}$ & N/A & $\begin{array}{l}\text { Guideline does not specify which symptoms should } \\
\text { be monitored at follow-up visits. }\end{array}$ \\
\hline 10. Splints should be placed in neutral position & Concordant & \\
\hline $\begin{array}{l}\text { 11. An attempt at splinting should last at least six } \\
\text { weeks }\end{array}$ & Somewhat Concordant & $\begin{array}{l}\text { Guideline states that an attempt at splinting can last } \\
\text { about four weeks before steroid injections is } \\
\text { attempted }\end{array}$ \\
\hline \multicolumn{3}{|l|}{ Certain medications should not be used for CTS } \\
\hline 12. NSAIDs & Discordant & $\begin{array}{l}\text { Guideline recommends NSAIDs for hand disorders } \\
\text { in general, states that corticosteroids may be more } \\
\text { effective than NSAIDs for CTS, but notes that the } \\
\text { side effects of steroids are a concern }\end{array}$ \\
\hline
\end{tabular}


Table 4 continued

\begin{tabular}{lll}
\hline RAND/UCLA measure title & $\begin{array}{l}\text { Concordance with } \\
\text { ACOEM guideline }\end{array}$ & Comments \\
\hline
\end{tabular}

13. Muscle relaxants

14. Opioids

15. Diuretics

16. Lasers should not be used for CTS

17. Discuss benefits of surgery when offering steroids to patients with severe CTS

18. First time steroid treatment requires discussion of risks

19. Steroids for work-associated symptoms require follow-up

20. Limit steroid injections to 4

21. New CTS diagnosis requires detailed occupational history

22. New CTS diagnosis requires assessment of occupational factors

23. New CTS diagnosis requires assessment of nonoccupational factors

24. Exacerbating activities should be identified when CTS limits functioning

25. Rationale for work-association should be documented

26. Patients diagnosed with CTS should be educated about the condition

27. Exposures to vibration, force, and repetition should be minimized

28. Work-associated CTS symptoms require prompt follow-up

29. Work status should be monitored when CTS appears work associated

30. Return to work after CTS-related disability requires follow-up assessment

31. Prolonged CTS-related disability should trigger evaluation

\section{N/A}

N/A

N/A

Concordant

N/A

N/A

Somewhat Concordant

Concordant

Concordant

Concordant

N/A

Concordant

Concordant

Concordant

Somewhat Concordant

Somewhat Concordant

Concordant

Somewhat Concordant

Concordant
Guideline does not mention the use of muscle relaxants for CTS

Guideline considers a short course of opiods to be an option for hand disorders in general but does not discuss the use of opioids for CTS

Guideline does not mention the use of diuretics for CTS

Guideline recommends that follow-up visits for work-related CTS be performed at a frequency of 4-7 or 7-14 days, depending upon whether the patient is working. The measure sets the minimum acceptable standard for follow-up at 4 weeks after the injection.

Guideline suggests steroid injections should be used for 8-12 weeks but does not specify the number of injections, whereas the measures specify the number but not the total duration of use.

The CTS chapter in guideline does not specify how to assess occupational factors. The ACOEM Return to Work Position Statement provides more specific recommendations [69].

Guideline does not discuss assessing nonoccupational factors that may be associated with the CTS symptoms.

Guideline is less specific about how patients should be educated.

Guideline mentions force and repetition but not vibration.

Guideline recommends that all follow-up visits for work-related CTS be performed at a frequency of 4-7 or 7-14 days, depending upon whether the patient is working. The measure sets the minimum acceptable standard for follow-up frequency at 4 weeks.

Guideline does not specify a time frame for followup in this specific situation. Its overall recommended frequency for follow-up would suggest within 4-7 days, whereas the measure sets the minimum acceptable standard at 4 weeks after return to work. 
When patients with CTS have a delayed returned to work after being on disability, physicians should identify and, when possible, treat any issues that may be interfering with recovery. Medical conditions that prior studies have identified as risk factors for delayed recovery among CTS patients include alcohol use, depression or anxiety, obesity, and smoking; although findings are not consistent across published studies [98, 99, 101-103]. Alcohol abuse and substance abuse are common and serious health problems that are challenging to detect, and the benefits of identifying them extend beyond facilitating return to work [104]. ACOEM guidelines and the position statement argue that healthcare providers can and should identify and intervene for other types of barriers to return to work [82, 100, 105].

\section{Comparison with Occupational Medicine Guidelines}

The table below compares the RAND/UCLA CTS measures with the ACOEM guideline [49]. As seen in the table, 17 measures (55\%) are fully concordant, five are somewhat concordant (16\%), the ACOEM guideline did not address content within eight of the measures (26\%), and one measure is discordant with the guideline $(3 \%)$. The measure that is discordant addresses the use of non-steroidal anti-inflammatory agents, for which recent literature has identified new risks. The RAND/UCLA measures are also largely concordant with a CTS guideline by the American Academy for Orthopedic Surgeons, although this guideline is much less detailed with respect to occupational issues [106, 107]. Table 4.

\section{References}

1. Tompa E, de Oliveira C, Dolinschi R, Irvin E. A systematic review of disability management interventions with economic evaluations. J Occup Rehabil. 2008;18(1):16-26.

2. Tompa E, de Oliveira C, dolinschi R, Irvin E. A systematic review of workplace ergonomic interventions with economic analyses. J Occup Rehabil. 2010;20(2):220-34.

3. Franche RL, Cullen K, Clarke J, Irvin E, Sinclair S, Frank J. Workplace-based return-to-work interventions: a systematic review of the quantitative literature. J Occup Rehabil. 2005; 15(4):607-31.

4. Abasolo L, Blanco M, Bachiller J, Candelas G, Collado P, Lajas $\mathrm{C}$, et al. A health system program to reduce work disability related to musculoskeletal disorders. Ann Intern Med. 2005; 143(6):404-14.

5. Department of Health and Human Services. Centers for Disease Control and Prevention. National Institute for Occupational Safety and Health. Worker Health Chartbook, 2004. Cincinnati, OH. DHHS (NIOSH) Publication No. 2004-146. Available at: http://www2a.cdc.gov/NIOSH-Chartbook/ch2/ch2-6-1.asp.
6. Daniell WE, Fulton-Kehoe D, Chiou LA, Franklin GM. Workrelated carpal tunnel syndrome in Washington State workers' compensation: temporal trends, clinical practices, and disability. Am J Ind Med. 2005;48(4):259-69.

7. U.S. Department of Labor: Bureau of Labor Statistics. Consumer price index, all urban consumers, 2000-2009. 2009.

8. Foley M, Silverstein B, Polissar N. The economic burden of carpal tunnel syndrome: long-term earnings of CTS claimants in Washington State. Am J Ind Med. 2007;50(3):155-72.

9. Townsend HB, Weaver MT, Brown KC, Saag KG, et al. Carpal tunnel syndrome guideline adherence by provider specialty (poster presentation). American College of Rheumatology Meeting; Washington, DC2006.

10. Weaver MT, Brown KC, Saag KG, Lee D. Carpal tunnel syndrome medical guideline adherence by specialty (abstract). American College of Rheumatology Annual Meeting; November 11-15; Washington, DC2006.

11. Graham B, Dvali L, Regehr G, Wright JG. Variations in diagnostic criteria for carpal tunnel syndrome among Ontario specialists. Am J Ind Med. 2006;49(1):8-13.

12. National Committee for Quality Assurance-A. Back pain recognition program. Criteria and scoring. Available at: http:// www.ncqa.org/tabid/169/Default.aspx. 2009 [cited 2009 August 2009]; Available from: Available at: http://www.ncqa.org/tabid/ 169/Default.aspx.

13. Fitch K, Bernstein SJ, Aguilar MD, Burnand B, LaCalle JR, Lazaro $\mathrm{P}$, et al. The RAND/UCLA appropriateness method user's manual. Santa Monica, CA: RAND Corporation2001. Report No.: MR-1269-DG-XII/RE.

14. U.S. Institute of Medicine. Committee for evaluating medical technologies in clinical use. Assessing medical technologies. Washington, DC: National Academy Press; 1985.

15. American Academy of Orthopaedic Surgeons (AAOS). Clinical guideline on diagnosis of carpal tunnel syndrome: guideline. Available at: http://www.aaos.org/Research/guidelines/guide. asp and http://www.aaos.org/Research/guidelines/CTS_guide line.pdf. Rosemont, IL2007; Available from: Available at: http:// www.aaos.org/Research/guidelines/guide.asp and http://www. aaos.org/Research/guidelines/CTS_guideline.pdf.

16. Higashi T, Shekelle PG, Adams JL, Kamberg CJ, Roth CP, Solomon DH, et al. Quality of care is associated with survival in vulnerable older patients. Ann Intern Med. 2005;143(4):274-81.

17. Hepner KA, Rowe M, Rost K, Hickey SC, Sherbourne CD, Ford $\mathrm{DE}$, et al. The effect of adherence to practice guidelines on depression outcomes. Ann Intern Med. 2007;147(5):320-9.

18. Quintana JM, Escobar A, Arostegui I, Bilbao A, Azkarate J, Goenaga JI, et al. Health-related quality of life and appropriateness of knee or hip joint replacement. Arch Intern Med. 2006;166(2):220-6.

19. Sandin KJ, Asch SM, Jablecki C, Kilmer D, Nuckols TK, Carpal Tunnel Quality Group. Clinical quality measures for electrodiagnosis in suspected carpal tunnel syndrome. Muscle Nerve. 2010;41:444-52.

20. Maggard M, Chang W, Harness N, Parikh JA, Asch SM, Chung $\mathrm{K}$, et al. Indications for performing carpal tunnel surgery: clinical quality measures. Plast Reconstr Surg. 2010; 126(1):169-79.

21. Nuckols TK, Wynn BO, Lim Y, Shaw RN, Mattke S, Wickizer $\mathrm{T}$, et al. Evaluating medical treatment guideline sets for injured workers in California. Santa Monica, CA: RAND Corporation2005. Report No.: MG-400-ICJ.

22. Shekelle PG. The appropriateness method. Med Decis Making. 2004;24(2):228-31.

23. Shekelle PG, Kahan JP, Bernstein SJ, Leape LL, Kamberg CJ, Park RE. The reproducibility of a method to identify the overuse 
and underuse of medical procedures. N Engl J Med. 1998; 338(26):1888-95.

24. American College of Occupational and Environmental Medicine (ACOEM). Occupational medicine practice guidelines: evaluation and management of common health problems and functional recovery in workers. 2nd ed. Elk Grove Village, IL: ACOEM; 2008.

25. Walter LC, Davidowitz NP, Heineken PA, Covinsky KE. Pitfalls of converting practice guidelines into quality measures: lessons learned from a VA performance measure. JAMA. 2004;291(20):2466-70.

26. Wickizer TM, Franklin G, Plaeger-Brockway R, Mootz RD. Improving the quality of workers' compensation health care delivery: the Washington State Occupational Health Services Project. Millbank Q. 2001;79(1):5-33.

27. Wilson d'Almeida K, Godard C, Leclerc A, Lahon G. Sickness absence for upper limb disorders in a French company. Occup Med (Lond). 2008;58(7):506-8.

28. Werner RM, Bradlow ET. Relationship between Medicare's hospital compare performance measures and mortality rates. JAMA. 2006;296(22):2694-702.

29. National Committee for Quality Assurance-B. What is HEDIS? 2009 [cited 2009 August]; Available from: Available at: http:// www.ncqa.org/tabid/187/Default.aspx.

30. Chang MH, Chiang HT, Lee SS, Ger LP, Lo YK. Oral drug of choice in carpal tunnel syndrome. Neurology. 1998;51(2): 390-3.

31. Scott PA, Kingsley GH, Smith CM, Choy EH, Scott DL. Nonsteroidal anti-inflammatory drugs and myocardial infarctions: comparative systematic review of evidence from observational studies and randomised controlled trials. Ann Rheum Dis. 2007;66(10):1296-304.

32. American College of Occupational and Environmental Medicine (ACOEM). The ACOEM Program for completion of Practice Performance (Part 4) of MAINTENANCE OF CERTIFICATION@ (MOC). Available at: http://www.acoem.org/moc.aspx. 2009; Available from: Available at: http://www.acoem.org/moc. aspx.

33. American Board of Preventive Medicine. Requirements for completion of the EPIQ Program. Available at: http://www. abprevmed.org/moc_requirements.cfm. Available from: Available at: http://www.abprevmed.org/moc_requirements.cfm.

34. MacLean CH, Louie R, Leake B, McCaffrey DF, Paulus HE, Brook RH, et al. Quality of care for patients with rheumatoid arthritis. JAMA. 2000;284(8):984-92.

35. Ganz DA, Chang JT, Roth CP, Guan M, Kamberg CJ, Niu F, et al. Quality of osteoarthritis care for community-dwelling older adults. Arthr Rheum. 2006;55(2):241-7.

36. Brook RH, McGlynn EA, Cleary PD. Quality of health care. Part 2: measuring quality of care. N Engl J Med. 1996;335(13): 966-70.

37. Field M, Lohr K. Clinical practice guidelines: directions for a new program. Washington, D.C: National Academies Press; 1990.

38. Cabana MD, et al. Why don't physicians follow clinical practice guidelines? A framework for improvement. JAMA. 1992;282(15): $1458-65$

39. Stevens JC, Smith BE, Weaver AL, Bosch EP, Deen HG Jr, Wilkens JA. Symptoms of 100 patients with electromyographically verified carpal tunnel syndrome. Muscle Nerve. 1999; 22(10): 1448-56.

40. Zanette G, Marani S, Tamburin S. Extra-median spread of sensory symptoms in carpal tunnel syndrome suggests the presence of pain-related mechanisms. Pain. 2006;122(3):264-70.

41. American Academy of Neurology. American Association of Electrodiagnostic Medicine. American Academy of Physical
Medicine and Rehabilitation. Practice parameter for electrodiagnostic studies in carpal tunnel syndrome (summary statement). Neurology. 1993;43(11):2404-2405.

42. Caliandro P, La Torre G, Aprile I, et al. Distribution of paresthesias in carpal tunnel syndrome reflects the degree of nerve damage at wrist. Clin Neurophysiol. 2006;117(1):228-31.

43. Katz JN, Larson MG, Sabra A, et al. The carpal tunnel syndrome: diagnostic utility of the history and physical examination findings. Ann Intern Med. 1990;112(5):321-7.

44. Katz JN, Stirrat CR, Larson MG, Fossel AH, Eaton HM, Liang MH. A self-administered hand symptom diagram for the diagnosis and epidemiologic study of carpal tunnel syndrome. J Rheumatol. 1990;17(11):1495-8.

45. Gupta SK, Benstead TJ. Symptoms experienced by patients with carpal tunnel syndrome. Can J Neurol Sci. 1997;24(4):338-42.

46. D'Arcy CA, McGee S. The rational clinical examination does this patient have carpal tunnel syndrome? JAMA. 2000;283(23): 3110-7.

47. Kuhlman KA, Hennessey WJ. Sensitivity and specificity of carpal tunnel syndrome signs. Am J Phys Med Rehabil. 1997; 76(6):451-7.

48. Daniell WE, Fulton-Kehoe D, Chiou LA, Franklin GM. Workrelated carpal tunnel syndrome in Washington State workers' compensation: temporal trends, clinical practices, and disability. Am J Ind Med. 2005;48(4):259-69.

49. American College of Occupational and Environmental Medicine. Occupational medicine practice guidelines: evaluation and management of common health problems and functional recovery in workers, 2nd Edition. Beverly Farms, MA; 2004.

50. Geoghegan JM, Clark DI, Bainbridge LC, Smith C, Hubbard R. Risk factors in carpal tunnel syndrome. J Hand Surg [Br]. 2004;29(4):315-20.

51. Solomon DH, Katz JN, Bohn R, Mogun H, Avorn J. Nonoccupational risk factors for carpal tunnel syndrome. J Gen Intern Med. 1999;14(5):310-4.

52. Pazzaglia C, Caliandro P, Aprile I, et al. Multicenter study on carpal tunnel syndrome and pregnancy incidence and natural course. Acta Neurochir Suppl. 2005;92:35-9.

53. de Krom MC, Knipschild PG, Kester AD, Spaans F. Efficacy of provocative tests for diagnosis of carpal tunnel syndrome. Lancet. 1990;335(8686):393-5.

54. Stevens JC, Beard CM, O'Fallon WM, Kurland LT. Conditions associated with carpal tunnel syndrome. Mayo Clin Proc. 1992; 67(6):541-8.

55. Golding DN, Rose DM, Selvarajah K. Clinical tests for carpal tunnel syndrome: an evaluation. Br J Rheumatol. 1986;25(4): 388-90.

56. American College of Occupational and Environmental Medicine (ACOEM). Occupational medicine practice guidelines: evaluation and management of common health problems and functional recovery in workers, 2nd edition. Elk Grove Village, IL: ACOEM; 2008.

57. Mühlau G, Both R, Kunath H. Carpal tunnel syndrome-course and prognosis. J Neurol. 1984;231(2):83-6.

58. Kulick MI, Gordillo G, Javidi T, Kilgore ES Jr, Newmayer WL 3rd. Long-term analysis of patients having surgical treatment for carpal tunnel syndrome. J Hand Surg [Am]. 1986;11(1):59-66.

59. Atroshi I, Johnsson R, Ornstein E. Patient satisfaction and return to work after endoscopic carpal tunnel surgery. J Hand Surg [Am]. 1998;23(1):58-65.

60. Nathan PA, Istvan JA, Meadows KD. A longitudinal study of predictors of research-defined carpal tunnel syndrome in industrial workers: findings at 17 years. J Hand Surg [Br]. 2005; 30(6):593-8.

61. American Association of Electrodiagnostic Medicine., American Academy of Neurology., American Academy of Physical 
Medicine and Rehabilitation. Practice parameter for electrodiagnostic studies in carpal tunnel syndrome: summary statement. Muscle Nerve. 2002;25(6):918-922.

62. American Academy of Orthopaedic Surgeons (AAOS). Diagnosis of Carpal Tunnel Syndrome: Evidence Report. Published 2007. Available at: http://www.aaos.org/Research/guidelines/ guide.asp and http://www.aaos.org/Research/guidelines/CTS_ body.pdf.

63. Cheadle A, Franklin G, Wolfhagen C, et al. Factors influencing the duration of work-related disability: a population-based study of Washington State workers' compensation. Am J Pub Health. 1994;84(2):190-6.

64. Dammers JW, Veering MM, Vermeulen M. Injection with methylprednisolone proximal to the carpal tunnel: randomised double blind trial. BMJ. 1999;319(7214):884-6.

65. Girlanda P, Dattola R, Venuto C, Mangiapane R, Nicolosi C, Messina C. Local steroid treatment in idiopathic carpal tunnel syndrome: short- and long-term efficacy. J Neurol. 1993;240(3): 187-90.

66. Hui AC, Wong SM, Tang A, Mok V, Hung LK, Wong KS. Long-term outcome of carpal tunnel syndrome after conservative treatment. Int J Clin Pract. 2004;58(4):337-9.

67. Burke DT, Burke MM, Stewart GW, Cambré A. Splinting for carpal tunnel syndrome: in search of the optimal angle. Arch Phys Med Rehabil. 1994;75(11):1241-4.

68. Werner RA, Franzblau A, Gell N. Randomized controlled trial of nocturnal splinting for active workers with symptoms of carpal tunnel syndrome. Arch Phys Med Rehabil. 2005;86: $1-7$.

69. Walker WC, Metzler M, Cifu DX, Swartz Z. Neutral wrist splint in carpal tunnel syndrome: a comparison of night-only versus full-time wear instructions. Arch Phys Med Rehabil. 2000; 81(4):424-9.

70. Chang MH, Chiang HT, Lee SS, Ger LP, Lo YK. Oral drug of choice in carpal tunnel syndrome. Neurology. 1998;51(2):390-3.

71. Scott PA, Kingsley GH, Smith CM, Choy EH, Scott DL. Nonsteroidal anti-inflammatory drugs and myocardial infarctions: comparative systematic review of evidence from observational studies and randomised controlled trials. Ann Rheum Dis. 2007;66(10):1296-304.

72. Celiker R, Arslan S, Inanici F. Corticosteroid injection vs. nonsteroidal antiinflammatory drug and splinting in carpal tunnel syndrome. Am J Phys Med Rehabil. 2002;81(3):182-6.

73. Ozdogan H, Yazici $\mathrm{H}$. The efficacy of local steroid injections in idiopathic carpal tunnel syndrome: a double-blind study. Br J Rheumatol. 1984;23(4):272-5.

74. Wong SM, Hui AC, Tang A, et al. Local versus systemic corticosteroids in the treatment of carpal tunnel syndrome. Neurology. 2001;56(11):1565-7.

75. Hui AC, Wong S, Leung $\mathrm{CH}$, et al. A randomized controlled trial of surgery vs. steroid injection for carpal tunnel syndrome. Neurology. 2005;64(12):2074-8.

76. McConnell JR, Bush DC. Intraneural steroid injection as a complication in the management of carpal tunnel syndrome. Clin Orthop Relat Res. 1990;250:181-4.

77. Gelberman RH, Aronson D, Weisman MH. Carpal-tunnel syndrome. Results of a prospective trial of steroid injection and splinting. J Bone Joint Surg Am. 1980;62(7):1181-4.

78. Gerritsen AAM, de Vet HCW, Scholten RJPM, Bertelsmann FW, de Krom MCTFM, Bouter LM. Splinting versus surgery in the treatment of carpal tunnel syndrome a randomized controlled trial. JAMA. 2002;288(10):1245-51.

79. Ly-Pen D, Andreu JL, de BG, Sanchez-Olaso A, Millan I. Surgical decompression versus local steroid injection in carpal tunnel syndrome: a one-year, prospective, randomized, open, controlled clinical trial. Arthr Rheum. 2005;52(2):612-9.
80. Wong SM, Hui AC, Lo SK, Chiu JH, Poon WF, Wong L. Single vs two steroid injections for carpal tunnel syndrome: a randomised clinical trial. Int J Clin Pract. 2005;59(12):1417-21.

81. Irvine J, Chong SL, Amirjani N, Chan KM. Double-blind randomized controlled trial of low-level laser therapy in carpal tunnel syndrome. Muscle Nerve. 2004;30(2):182-7.

82. American College of Occupational and Environmental Medicine. ACOEM Guideline: Preventing Needless Work Disability by Helping People Stay Employed. Available at: http://www. acoem.org/guidelines.aspx?id=566. Accessed July 22, 2007.

83. Talmadge JB, Melhorne JM. How to think about work ability and work restrictions: risk, capacity, and tolerance. In: Talmadge JB, Melhorn JM, editors. A physician's guide to return to work. Chicago, IL: American Medical Association Press; 2005.

84. Palmer KT, Harris EC, Coggon D. Carpal tunnel syndrome and its relation to occupation: a systematic literature review. Occup Med (Lond). 2007;57(1):57-66.

85. Werner RA. Evaluation of work-related carpal tunnel syndrome. J Occup Rehabil. 2006;16(2):207-22.

86. National Institute for Occupational Safety and Health. Hand/ wrist musculoskeletal disorders (carpal tunnel syndrome, tendinitis, hand-arm vibration syndrome): evidence for workrelatedness. In: Bernard BP, editor. Musculoskeletal disorders and workplace factors, a critical review of epidemiologic evidence for work-related musculoskeletal disorders of the neck, upper extremity, and low back. Cincinnati, OH: NIOSH; 1997.

87. Silverstein BA, Fine LJ, Armstrong TJ. Occupational factors and carpal tunnel syndrome. Am J Ind Med. 1987;11(3):343-58.

88. Cannon LJ, Bernacki EJ, Walter SD. Personal and occupational factors associated with carpal tunnel syndrome. J Occup Med. 1981;23(4):255-8.

89. Hudak PL, Amadio PC, Bombardier C. Development of an upper extremity outcome measure: the DASH (disabilities of the arm, shoulder and hand) [corrected]. The Upper Extremity Collaborative Group (UECG). Am J Ind Med. 1996;29(6): 602-8.

90. Chung KC, Pillsbury MS, Walters MR, Hayward RA. Reliability and validity testing of the Michigan Hand Outcomes Questionnaire. J Hand Surg Am. 1998;23(4):575-87.

91. Levine DW, Simmons BP, Koris MJ, et al. A self-administered questionnaire for the assessment of severity of symptoms and functional status in carpal tunnel syndrome. J Bone Joint Surg Am. 1993;75(11):1585-92.

92. U.S. Department of Labor: Occupational Safety and Health Administration. OSHA forms for recording occupational illnesses and injuries. Available at: http://www.osha.gov/record keeping/new-osha300form1-1-04.pdf. Accessed July 22, 2007.

93. Washington State Department of Labor and Industries. Medical treatment guidelines, F252-010-000. Chapter: diagnoses and treatment of work-related carpal tunnel syndrome (OCTS), p. 32. Available at: http://www.lni.wa.gov/ClaimsIns/Files/OMD/ MedTreat/CarpalTunnel.pdf. Accessed July 22, 2007.

94. State of California: Division of workers' compensation. Doctor's first report of occupational injury or illness. Available at: http://www.dir.ca.gov/dlsr/dlsrform5021.pdf. Accessed July 22, 2007.

95. Genovese E. Causation analysis. In: Talmadge JB, Melhorn JM, editors. A physician's guide to return to work. Chicago, IL: American Medical Association Press; 2005.

96. URAC. Measuring Quality in Workers' Compensation Managed Care Organizations: Technical manual of performance measures. Available at: http://www.urac.org/savedfiles/WorkersComp PerformanceMeasures.pdf.

97. Franklin G. Deliverable 6B: Report on recommended quality indicators. Seattle, WA: Prepared for: Occupational Health Services Project, Washington State Department of Labor and 
Industries. University of Washington, School of Public Health and Community Medicine, Department of Environmental Health, Occupational Epidemiology and Health Outcomes Program; May 92001.

98. Katz JN, Amick BC 3rd, Keller R, et al. Determinants of work absence following surgery for carpal tunnel syndrome. Am J Ind Med. 2005;47(2):120-30.

99. Amick BC 3rd, Habeck RV, Ossmann J, Fossel AH, Keller R, Katz JN. Predictors of successful work role functioning after carpal tunnel release surgery. J Occup Environ Med. 2004;46(5): 490-500.

100. American College of Occupational and Environmental Medicine (ACOEM). Position Statement: The attending physician's role in helping patients return to work after an illness or injury. Available at: http://www.acoem.org/guidelines.aspx?id=744. Accessed July 22, 2007.

101. Katz JN, Losina E, Amick BC 3rd, Fossel AH, Bessette L, Keller RB. Predictors of outcomes of carpal tunnel release. Arthr Rheum. 2001;44(5):1184-93.

102. Katz JN, Keller RB, Fossel AH, Punnett L, Bessette L, Simmons BP, Mooney N. Predictors of return to work following carpal tunnel release. Am J Ind Med. 1997;31(1):85-91.
103. Katz JN, Keller RB, Simmons BP, et al. Maine carpal tunnel study: outcomes of operative and nonoperative therapy for carpal tunnel syndrome in a community-based cohort. J Hand Surg [Am]. 1998;23(4):697-710.

104. McGlynn EA, Asch SM, Adams J, et al. The quality of health care delivered to adults in the United States. N Engl J Med. 2003;348(26):2635-45.

105. American College of Occupational and Environmental Medicine (ACOEM). Occupational medicine practice guidelines: evaluation and management of common health problems and functional recovery in workers, 2nd Edition. Beverly Farms, MA: OEM Press; 2003.

106. American Academy of Orthopaedic Surgeons (AAOS). 2007. Clinical guideline on diagnosis of carpal tunnel syndrome: guideline. Available at: http://www.aaos.org/Research/guidelines/ guide.asp and http://www.aaos.org/Research/guidelines/CTS_ guideline.pdf Rosemont, IL.

107. American Academy of Orthopaedic Surgeons (AAOS). 2008 Clinical practice guideline on the treatment of carpal tunnel syndrome. Available at: http://www.aaos.org/Research/guide lines/CTSTreatmentGuideline.pdf. 